\title{
Tobacco Control Policies in Vietnam: Review on MPOWER Implementation Progress and Challenges
}

\author{
Hoang Van Minh ${ }^{1 *}$, Tran Thu Ngan ${ }^{1}$, Vu Quynh Mai ${ }^{1}$, Nguyen Thi Tuyet $\mathbf{M y}^{1}$, \\ Le Hong Chung ${ }^{1}$, Vu Duy Kien ${ }^{1}$, Tran Tuan Anh ${ }^{1}$, Nguyen Bao Ngoc ${ }^{1}$, Vu Van \\ Giap $^{2}$, Nguyen Manh Cuong ${ }^{3}$, Pham Duc Manh ${ }^{3}$, Kim Bao Giang ${ }^{2}$
}

\begin{abstract}
In Vietnam, the WHO Framework Convention on Tobacco Control (WHO FCTC) took effect in March 2005 while MPOWER has been implemented since 2008. This paper describes the progress and challenges of implementation of the MPOWER package in Vietnam. We can report that, in term of monitoring, Vietnam is very active in the Global Tobacco Surveillance System, completing two rounds of the Global Adult Tobacco Survey (GATS) and three rounds of the Global Youth Tobacco Survey (GYTS). To protect people from tobacco smoke, Vietnam has issued and enforced a law requiring comprehensive smoking bans at workplaces and public places since 2013. Tobacco advertising and promotion are also prohibited with the exception of points of sale displays of tobacco products. Violations come in the form of promotion girls, corporate social responsibility activities from tobacco manufacturers and packages displayed by retail vendors. Vietnam is one of the 77 countries that require pictorial health warnings to be printed on cigarette packages to warn about the danger of tobacco and the warnings have been implemented effectively. Cigarette tax is $70 \%$ of factory price which is equal to less than $45 \%$ of retail price and much lower than the recommendation of WHO. However, Vietnam is one of the very few countries that require manufacturers and importers to make "compulsory contributions" at 1-2\% of the factory price of cigarettes sold in Vietnam for the establishment of a Tobacco Control Fund (TCF). The TCF is being operated well. In 2015, 67 units of 63 provinces/cities, 22 ministries and political-social organizations and 6 hospitals received funding from TCF to implement a wide range of tobacco control activities. Cessation services have been starting with a toll-free quit-line but need to be further strengthened. In conclusion, Vietnam has constantly put efforts into the tobacco control field with high commitment from the government, scientists and activists. Though several remarkable achievements have been gained, many challenges remain. To overcome those challenges, implementation strategies that take into account the contextual factors and social determinants of tobacco use in Vietnam are needed.
\end{abstract}

Keywords: Tobacco policy - MPOWER - WHO Framework Convention on Tobacco Control - Vietnam

Asian Pac J Cancer Prev, 17 Tobacco Prevention and Control in Vietnam Suppl, 1-9

\section{Introduction}

Tobacco is the only legal consumer product that can kill people when it is used in accordance with manufacturer's instruction (World Health Organization, 2008). According to WHO, tobacco kills one person every six seconds (Mathers and Loncar, 2006). Annually, while active smoking kills more than 5 million people, secondhand smoking (SHS) causes the death of over 600,000 people worldwide (U.S. Department of Health and Human Services and Centers for Disease Control and Prevention, 2010). If the situation is not improved, tobacco death toll will reach 8 million per year by 2030 and the vast majority of these deaths are projected to occur in the developing world (World Health Organization, 2008).
Viet Nam is one of the countries that have the highest number of male smokers in the world with $47.4 \%$ of men currently smoke (smoking prevalence in women is $1.4 \%$ ) (Vietnam Ministry of Health et al., 2010). About $73.1 \%$ of adults aged 15 years and above said they were exposed to SHS at home (Vietnam Ministry of Health et al., 2010). Tobacco use is a leading cause of death in Viet Nam. The number of annual deaths that is attributed to only three major tobacco-related diseases (lung cancer, chronic obstructive pulmonary disease and stroke) is greater than that of all of these combined: HIV/AIDS, tuberculosis and traffic accidents (Mokdad et al., 2004; Levy et al., 2006; Centers for Disease Control and Prevention, 2008). A simulation model developed for Viet Nam estimated that nearly 40,000 deaths were attributed to smoking in 2008

${ }^{1}$ Hanoi School of Public Health, ${ }^{2}$ Hanoi Medical University, ${ }^{3}$ Ministry of Health, Hanoi, Vietnam *For correspondence: hvm@ hsph.edu.vn 
(Levy et al., 2006). A recent study estimated that smoking incurred more than 1.1 billion USD of healthcare cost and productivity cost in Viet Nam each year (Anh et al., 2014)

In order to counter the tobacco epidemic, tobacco control policies are crucial. To strengthen policies, programs and strategies that prevent and reduce tobacco use, the WHO Framework Convention on Tobacco Control (WHO FCTC) was adopted by the 56th World Health Assembly on 21 May 2003. The treaty came into effect on 27 February 2005 as a response to the global tobacco epidemic. Having been signed by 168 countries and is legally binding in 180 countries, FCTC is "the most rapidly and widely embraced treaty in United Nations history". In 2008, WHO introduced MPOWER - a package of 6 proven measures to reduce tobacco prevalence worldwide. The MPOWER package includes 1) Monitor tobacco use and prevention policies; 2) Protect people from tobacco smoke; 3 ) Offer help to quit tobacco use; 4) Warn about the dangers of tobacco; 5) Enforce bans on tobacco advertising, promotion and sponsorship; and 6) Raise taxes on tobacco.

MPOWER is proved by WHO as practical, affordable and achievable demand-reduction interventions for effective tobacco control (World Health Organization, 2008). A review in 2014 showed that after 5 years of implementation more than 2.8 billion people worldwide have been covered by at least 1 MPOWER measure at the highest level (World Health Organization, 2015b). Among high-achieving countries, Turkey is an outstanding example being the first country in the world to achieve all six MPOWER measures at the highest level. Along with the remarkable $13.4 \%$ decline in smoking prevalence is the $20 \%$ decline in the number of citizens admitted to hospital for smoking-related diseases (World Health Organization, 2013). However, not many countries were as successful. Different countries have gained a wide range of different achievements, depending on the support they had and the barriers they faced.

In Vietnam, FCTC took effect in March 2005 while the MPOWER has been implemented since 2008. The effectiveness of each individual policy had been evaluated in some studies. However, the overview of the MPOWER package in Vietnam as a whole has not been reviewed yet. Therefore, the aim of this paper is to describe the progress and challenges of implementation of MPOWER package in Vietnam.

\section{Materials and Methods}

This is a critical narrative literature review in which data information was obtained from peer-reviewed articles, official government documents, reports, decrees and grey literature in both English and Vietnamese.

\section{Search strategy and data sources}

Both online and manual search methods were used to collect the information. In terms of online search, the author used two main search engines PubMed and Google Scholar along with online databases of WHO and Vietnam Steering Committee on Smoking and Health (Vinacosh). Main keywords in use were "policies", "MPOWER", "tobacco control", "Vietnam". Boolean AND/OR were used along with those keywords to search for documents combined. Detail keywords used for each component of MPOWER package can be found in Table 1 .

Manual search was carried out to obtain unpublished literature, including reports by research institutes/ Vinacosh and government/non-governmental documents as well as legal documents including tobacco control Law, corresponding decrees, circular and related official documents.

\section{Study selection and inclusion/exclusion criteria}

All types of literature including research report, literature review, journal article, fact sheet, government documents, decrees and thesis were included. Generally, the limit on the time of publication is 10 years. Exceptions were made for books and textbooks. Both English and Vietnamese literature were used.

\section{Results}

Key milestones in terms of tobacco control policies in Vietnam

The first comprehensive legal framework for tobacco control in Vietnam is the National Tobacco Control Policy 2000 - 2010, approved by Resolution No 12/2000/NQ-CP which was signed by the Prime Minister (Vietnamese Government, 2000). Under this National Policy, VINACOSH was strengthened and given more proper role and power to coordinate tobacco control in Vietnam.

On 3rd Sep 2003, Vietnam signed the WHO Framework Convention on Tobacco Control (FCTC) and ratified it on 17th Dec 2004. One year after, on 17th March 2005, the FCTC officially took effect. In 2008, WHO introduced MPOWER package, each of which reflects one or more of the demand reduction provisions of the WHO FCTC. The first Vietnamese comprehensive law on tobacco control - Law on Prevention and Control of Tobacco Harms (2012 TC Law) - was approved by the National Assembly of Vietnam on 18th June 2012. It took effect on 1st May 2013.

Table 1. Details of Keywords Used for Searching Each Component of the MPOWER Package

\begin{tabular}{cc}
\hline Topics & Addition keywords (along with the main keywords) \\
\hline M - Monitor use and policies & "monitoring" "gats" "gyts" "surveillance system" \\
P - Protect from secondhand smoke & "tobacco free" "secondhand smoke" \\
O - Offer help to quit tobacco use & "quitline" "offer to quit" "NRT" \\
W - Warn of dangers & "pictorial health warning" "graphic health warning" \\
E - Enforce TAPS ban & "tobacco advertising" "tobacco promotion" "tobacco sponsorship" "TAPS ban" \\
R - Raise taxes on tobacco & "tobacco tax implementation" "Tobacco Control Fund"
\end{tabular}


Monitor tobacco use and prevention policies (corresponding to Article 20 FCTC - Research, surveillance and exchange of information)

Before 2007, monitoring-related activities for tobacco use had been combined with several national surveys such as The Vietnam Living Standards Survey from 1992 and 1998; The Vietnam National Health Survey 2002; and The Vietnam Household Living Standards Survey from 2006.

Recently, Vietnam became involved in the Global Surveillance System on Tobacco which systematically monitors adult tobacco use and tracks tobacco control indicators for both adults and adolescents. Global Surveillance Surveys conducted in Vietnam includes The Global Adult Tobacco Survey (GATS, in 2010 and 2015) and the Vietnam Global Youth Tobacco Survey on students aged 13-15 years (GYTS, in 2007 and 2014).

Therefore, key information on tobacco use including smoking prevalence, second-hand smoking, cessation, media, etc. has been continuously updated and monitored. The National Health Survey 2002 (Vietnam Ministry of Health, 2002) estimated that smoking rate was 56\% among adult males and 1.5 among adult females. According to the result of GATS 2010, the smoking prevalence in general was $23.8 \%$ (about 15.3 million adults) in which the rates of men and women were $47.4 \%$ and $1.4 \%$, respectively. Among smokers, $81.8 \%$ smoked daily, $83.7 \%$ used cigarettes, $26.9 \%$ smoked water pipes and only $1.3 \%$ used smokeless tobacco. The average age of starting daily smoking in general is 19.9 years old and the ages of smoking initiation for men and women are 19.8 and 23.6 years old, respectively (Vietnam Ministry of Health et al., 2010). Compared with 2002, there seem to be sizable reduction in smoking rate among adults. However, the two survey employed different methodology, we should interpret the reduction with caution.

Moreover, GYTS surveys also provided us youth tobacco use - related information. In general, tobacco use among school children aged $13-15$ is $2.5 \%$ (4.9\% for boys and $0.2 \%$ for girls) (Vietnam Ministry of Health et al., 2014). This is a significant reduction in youths smoking rate compared with the corresponding rate of $3.3 \%(5.9 \%$ for boys and $1.2 \%$ for girls) in the previous Viet Nam's 2007 GYTS survey (Van Minh et al., 2011).

Protect people from secondhand smoke (corresponding to Article 8 from FCTC - Protection from exposure to tobacco smoke)

Since 1989, smoking bans in halls, cinema and theatres had been included in the Law on the Protection of People's Health (National Assembly of Vietnam, 1989). Smoking was also banned in army in 1996 while tobacco sponsorship of sports \& culture events was banned in 1997.

Resolution No. 12 of the Government in the National Policy on Tobacco Control for the period of $2000-2010$ included the objective 4 "ensure the rights of nonsmokers to live in a smoke-free atmosphere" (Vietnamese Government, 2000). This resolution emphasizes the regulations of smoke-free public venues by prohibiting smoking at meetings, in offices, in theatres and on public transportation. Based on Decree No. 45/2005/ND-CP of the Prime Minister on Regulation on Sanctioning of Administrative Violations in the Health Sector, fine for violations is from 50,000 to 100,000 VND (US\$3-\$6) (Vietnamese Government, 2005).

The implementation of smoke-free environment was given a boost with the issuance of the National Action Plan for the Implementation of the WHO Framework Convention on Tobacco Control (The Prime Minister of Vietnam, 2009). However, the most comprehensive ban of smoking in public and workplaces was promulgated in the 2012 TC Law which took effect on 1 May 2013. The Law established smoke-free places including: health and educational settings; child care and entertainment areas designated for children; areas at high risk of fire and/or explosion; indoor workplaces; universities, colleges and other academic institutions; restaurants; public transport (automobiles, airplanes and sky train/metro) (National Assembly of Vietnam, 2012). The fines for violations were also clearly defined in the Decree No 176/2013/ND-CP on administrative sanctions for violations in the health sector (Vietnamese Government, 2013a).

Up to now, implementation of tobacco free environment has been widely established in different settings. However, the implementation result is not the same for all places. Some settings implemented better than others. From the result of Global Adult Tobacco Survey in 2010, the proportion of smoking in bars/cafes/tea shops was highest with $92.6 \%$ followed by restaurants with $84.9 \%$. For indoor workplaces, the prevalence rate of smoking in the past 30 days was $55.9 \%$. The lowest proportion of smoking occurrence was in universities and government office buildings with $54.3 \%$ and $38.7 \%$, respectively (Vietnam Ministry of Health et al., 2010).

In the WHO MPOWER report 2015 (World Health Organization, 2015b), based on experts' opinion, the compliance with smoke-free environment in Vietnam is classified as moderate with 4 points out of the perfect 10. For comparison, the level of compliance was lower at 1 point out of 10 in 2009 and 3 points out of 10 in 2011 (World Health Organization, 2009; World Health Organization, 2011).

Offer help to quit tobacco use (Corresponding to Article 14- Demand reduction measures concerning tobacco dependence and cessation)

The 2012 TC law included sections to develop the tobacco cessation services. The 77 th Decree of the Government, which regulated the two mentioned sections in detail, had been issued 2 months after the official law's enactment.

Study showed that everyone will occasionally take medical visits to health centers. That is the reason why repeating the advice about tobacco harm during each visit would be quite effective since the consultants are well respected health professionals (Solberg et al., 2006). Report of GATS 2010 showed that only $29 \%$ of smokers received advice from health staffs to quit smoking and only $3.0 \%$ of smokers sought counseling advice to help them stop smoking (Vietnam Ministry of Health et al., 2010). Hence, the Vietnamese Government needs more actions to consolidate the services at center based. 
Following the 77 th decree, tobacco cessation treatment and counseling facilities are required to have some basic tools such as information, education and communication (IEC) materials, computer system in managing client's information, private room for tobacco control counseling, trained staffs and approved pharmacotherapy at the former organization (Vietnamese Government, 2013b). Together with cessation services at health care centers, quit lines can be described as an official system that is easy to access by smokers to get advices or support to quit smoking. Some case studies of quit line that support smokers have been conducted in Vietnam recently (Shelley et al., 2014). Pharmacological therapy to support smoking cessation includes two main types of products which are nicotine replacement therapy - NRT (nicotine gum, lozenge, and spray) and pharmacotherapy (Varenicline, Bupropion). According to the 2012 TC Law, all organizations that produce or import these mentioned products would receive preferential tariff defined in relevant regulations on import tax. The pharmacotherapy might be applied where else in tobacco cessations rehabs or campaigns in Vietnam. Report of GATS 2010 showed that among those who had made quit attempts or given up less than 12 months, $24.4 \%$ used NRT and $0.4 \%$ used prescription medications. Nevertheless, the Government has not issued any document related to neither trading the products nor including it into the national essential drugs list (World Health Organization, 2015a).

Vietnam has its own Tobacco Control Fund (TCF) to invest in strengthening the capacity of cessation services at both health care facilities and non - health care facilities (for instance, village health workers). At the moment cessation services are established in 5 hospitals and one toll-free quit line is established at Bach Mai Hospitals with 10 counsellors providing cessation advice through the phone. There is also a small-scale donor project on community-based smoking cessations in Thai Nguyen province providing cessation advice at the commune health stations and through home visits by village health workers (Shelley et al., 2015).

Warn of dangers (corresponding to Article 11-Packaging and labelling of tobacco products and Article 12 Education, communication, training and public awareness)

Regarding health warnings, it was a long and tough fight to get pictorial health warnings implemented in Viet

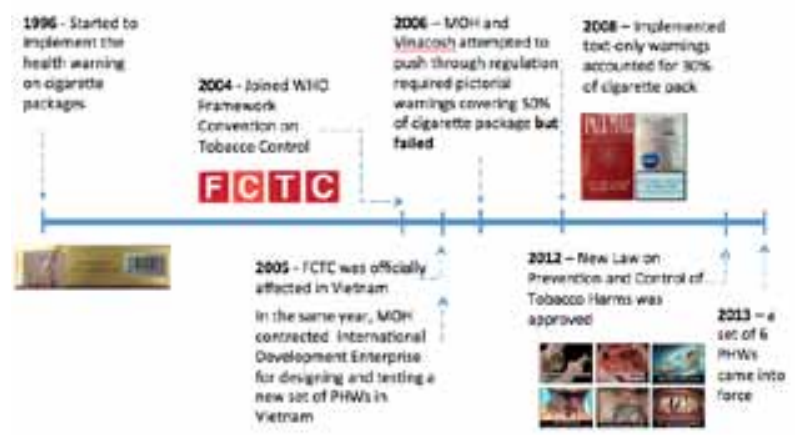

Figure 1. Timeline of Policies on Packaging and Labelling of Tobacco Products
Nam. In 1996, Vietnam started to print health warnings on cigarette packages (Vietnam Ministry of Health, 2000b). It was a small text-only warning on one side of the cigarette package. The tobacco manufacturers could choose to print either the warning "Smoking is harmful to health" or "Smoking causes lung cancer" on their products. In fact, most of the manufacturers chose the former warning as it is weaker although both versions of the health warnings were proved as ineffective in Vietnam (Vietnam Ministry of Health, 2000a; Duy, 2004).

On $17^{\text {th }}$ March 2005, the FCTC took effect in Vietnam. Article 11 of this Convention required every member parties to apply the health warning signs that occupied for at least $30 \%$ of the principal display surfaces of a cigarette pack and strongly encouraged member parties to use pictorial health warnings (World Health Organization, 2005). Deadline for implementation is 3 years from the date in which the Convention took effect in the country (World Health Organization, 2005).

Right after the effective date of FCTC in Vietnam, the Vietnam Ministry of Health $(\mathrm{MOH})$ funded by WHO signed a contract with International Development Enterprise in which this organization took responsibility for designing and testing a new set of pictorial health warnings in Vietnam (Ministry of Health and International Development Enterprise IDE, 2006). The survey was carried out cautiously in 3 rounds, using both quantitative and qualitative research. Based on the findings, $\mathrm{MOH}$ have selected 5 pictorial health warnings.

In 2006, VINACOSH-MOH attempted to push through a new regulation on pictorial warning labels on tobacco products that would cover $50 \%$ of cigarette package. However, the tobacco industry had successfully thwarted these efforts. As results, text-only health warnings which accounted for $30 \%$ of the principal surfaces of a cigarette package were approved, with one of the two messages chosen for the health warnings were "Smoking can cause lung cancer" and "Smoking can cause COPD". These textonly health warnings that met the minimum requirement of FCTC were launched in March 2008.

Studies conducted after that proved the ineffectiveness of this new set of warnings. One year after the implementation, only $39 \%$ of people (both smokers and non-smokers) could remember the warning "smoking can cause lung cancer" (Vietnam Ministry of Health and Center for Community Development and Research, 2009). Likewise, the warning "smoking can cause COPD" was remembered by only $6 \%$ of people (Vietnam Ministry of Health and Center for Community Development and Research, 2009). A quarter of the people even did not recognize that the health warning has been changed for a year (Vietnam Ministry of Health and Center for Community Development and Research, 2009). It indicated the weak salience of this new text-only warning set (Vietnam Ministry of Health and Center for Community Development and Research, 2009). Moreover, half of the smokers aged 15+ reported that they did notconcern about their health $(53.3 \%)$, that they did not feel scared $(50 \%)$ and the warnings did not lead to intentions of quitting (56.8\%) (Vietnam Ministry of Health and Center for Community Development and Research, 
2009).

In contrast, a large number of both Vietnamese smokers and non-smokers agreed on using the PHWs on cigarette packages. Specifically, $82.2 \%$ and $51.8 \%$ people claimed that PHWs which occupied for $50 \%$ and $70 \%$, respectively of a cigarette package's surface should be used (Vietnam Ministry of Health and Center for Community Development and Research, 2009). In another study, $77.3 \%$ people chose pictorial health warnings as the most appropriate type of health warning labels on cigarette package (Bich and Son, 2006).

After a long battle for quite a few years, and thanks to support from many partners to tobacco control in Vietnam, on 18th June 2012, Law on Prevention and Control of Tobacco Harms in which Article 15 required the printing of pictorial health warnings (PHW) on every cigarette packages was approved by the National Assembly of Vietnam (National Assembly of Vietnam, 2012). In May 2013, the new set containing of 6 graphic pictures and health messages covering 50\% of both the front and back of the cigarette package (Figure 2) came into effect (National Assembly of Vietnam, 2012).

Among 180 countries that are legally bound by FCTC, Vietnam is one of 77 countries that have successfully implemented the PHWs on cigarette package. PHWs in Vietnam are large (covering 50\% of the pack surface) and describe specific harmful effects of tobacco use on health along with rotation regulations.

On the side of communication and public awareness, with support from WHO and partners, Vietnam had implemented yearly World No Tobacco Day Celebration with participation of high profile public health experts and policy makers. In addition, there are many communication activities conducted at local level supported by TCF, VINACOSH and various partners. There were significant mass media communication campaigns conducted from 2010 with financial and technical support from the World Lung Foundation, WHO and other partners (World Lung Foundation, 2015).

As a result, WHO classified Vietnam as having the highest achievement on W-Warn about the danger of tobacco use in MPOWER package (World Health Organization, 2015a).
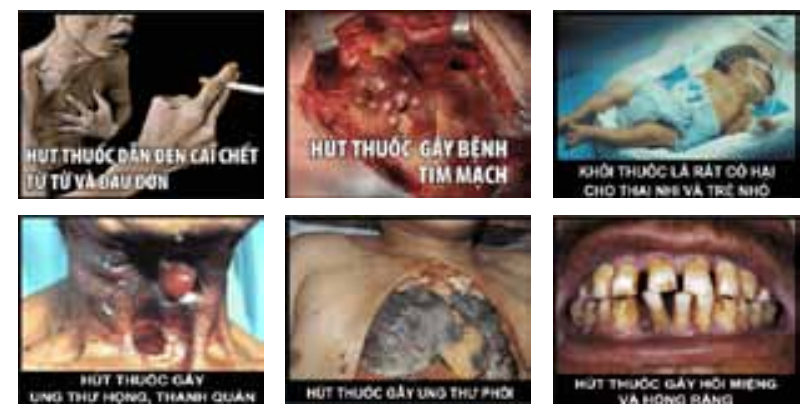

Figure 2. Pictorial health warning printed on cigarette packages in Vietnam since May 2013. From left to right, up to down: (1) Smoking leads to death slowly and painfully; (2) Smoking causes heart diseases; (3) Cigarette smoke is very harmful to fetus and young children; (4) Smoking causes throat and laryngeal cancer; (5) Smoking causes lung cancer; (6) Smoking causes bad breath and damaged tooth
Enforce TAPS ban (corresponding to Article 13-Tobacco advertising, promotion and sponsorship)

As early as in 1994, the government banned tobacco advertising on electronic and print media according to Decree 194-CP dated 31st December 1994 (Vietnamese Government, 1994). In 1995, the more stringent guidelines on the media advertising ban was established in Circular 37-VHTT-TT of the Ministry of Cultural, Information and Communication (Vietnam Ministry of Cultural Information and Communication, 1995). In 1997, tobacco sponsorship of sports and culture events was also prohibited. In 2000, bans on cigarette advertising, promotion and sponsorship were mentioned for the first time in the Decree on "National Policy on Tobacco Control 2000-2010" issued by the Government (Vietnamese Government, 2000). The advertising ban was consolidated under the Revised Trade Law 2005 which banned advertising of those products that belonged to the list "not encourage consumption of" which included tobacco. In 2007, the Government issued Directive No. 12/2007/CTTTg on strengthening tobacco control activities in Viet Nam, which banned cigarette advertising, sponsorships and marketing (The Prime Minister of Vietnam, 2007).

In 2012, the comprehensive Law on Tobacco Prevention and Control (Law No 09/2012/QH13) which banned all forms of direct and indirect tobacco advertising was approved by the National Assembly (National Assembly of Vietnam, 2012). Tobacco sponsorship was also banned by this Law (National Assembly of Vietnam, 2012), with the exceptions of sponsorship for philanthropies purposes and these are not allowed to be published in mass media.

On the compliance part, there is good compliance with the bans on advertising on mass media such as TV, newspapers and billboard. However, there are serious violations of advertising and promotion bans at point of sales. For examples, few surveys on TAPS at point of sales were conducted between 2010 and 2014 at more than 1,443 point of sales (POSs) in 10 provinces/cities throughout Vietnam. The surveys showed that, on average, more than $90 \%$ of observed POSs in 10 provinces/cities had tobacco advertising or promotion activities under various forms (Anh et al., 2010). The most common violation was displaying more than 1 package/carton of one brand of cigarette (more than 90\%). Other violations included tobacco push-carts, counters with colors/ logos/ trademarks of tobacco products, and colorful and attractive package, design features range from very low to about $30 \%$ of POS. There were occasional reports of sponsorship activities including art performances and other philanthropic activities such as building houses and provided loans for the poor (Anh et al., 2010).

In conclusion, in terms of policy content, evaluation from WHO classified Vietnam at the 4th level of achievement (with 1 as the lowest and 5 as the highest level of achievement) with bans on national TV, radio and print media as well as on some but not all other forms of direct and /or indirect advertising (World Health Organization, 2015a). In terms of compliance of TAPS bans, Vietnam was given 8 points out of 10 due to good compliance with the advertising ban on mass media. However, the 


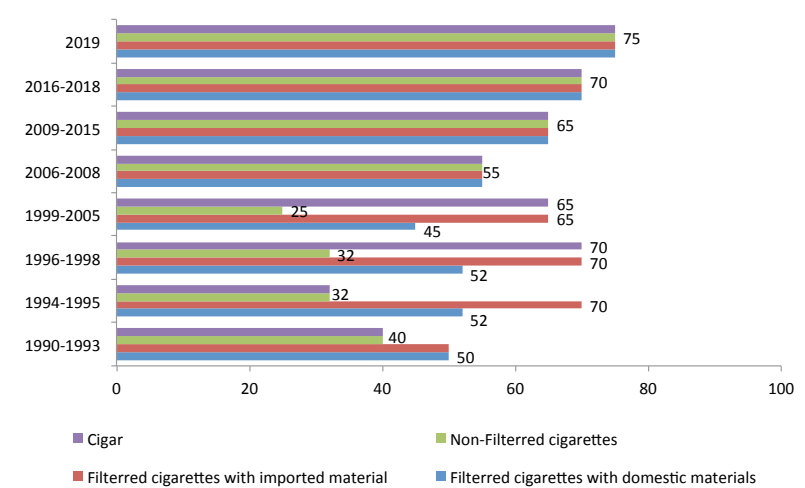

Figure 3. Special Consumption Tax Rate Based on Factory Price by Years (\%)

violations at point of sales are still quite serious and need strong enforcement action.

Raise taxes on tobacco (Corresponding to Article 6 - Price and tax measures to reduce the demand for tobacco)

The most effective way to reduce tobacco consumption is to raise its retail price. $70 \%$ higher of tobacco price would prevent up to $25 \%$ of all smoking-related deaths worldwide (Jamison et al., 2006).

Cigarettes and related products in Vietnam are subjected to tax under the ad valorem system. There are three main layers of taxation on tobacco, which are import duties, special consumption tax (SCT) which is the name for excise tax in Vietnam, and value added tax (VAT). The first layer of taxation is added into the CIF value (cost, insurance and freight) of imported cigarettes and tobacco materials. The second layer of the excise is charged on factory prices (pre-tax) of all types of cigarettes, which are sold in the domestic market (Ministry of Finance, 1998). The final layer is value added tax, which is charge at $10 \%$ of the tobacco's value including import tax value and SCT value.

For the import of cigarettes, as an official member or WTO since 2007, Vietnam must comply with WTO rules on trade and eliminate the prohibition on tobacco importation (The Ministry of Trade and The Ministry of Industry, 2007); thus cigarettes imports were allowed since then. However, Vietnam was allowed to apply high import tax on these import cigarettes. In addition, to control the quality of cigarettes and tobacco products, only Vietnam's state-owned company - VINATABA is allowed to import the products (Ministry of Industry and Trade, 2013). Cigarettes and cigars are now subject to an import duty rate of $135 \%$ of the merchandise's CIF value at the WTO "most favored nation" and of $225 \%$ of the CIF value for other countries.

In terms of the special consumption tax, before 2006, it was applied at three different levels: $25 \%$ for un-filtered cigarettes, $45 \%$ for filtered cigarettes made from mostly domestic materials and $65 \%$ for cigarettes made mostly from imported materials. The revised SCT law 2005 (National Assembly of Vietnam, 2005) provided a short road map to uniform level of SCT tax for all types of cigarettes sold in Viet Nam: 55\% for the period 2006-2007 and $65 \%$ from 2008. In 2014, the STC law was revised again and promulgated a roadmap for SCT until 2019. The rate of increase was, however, very insignificant, from $65 \%$ to $70 \%$ of factory price starting from 2016 and to $75 \%$ starting from 2019 (see Figure 3) (National Assembly of Vietnam, 2014).

Besides the three types of taxes above, it is specially worth mentioning that, the 2012 TC Law also approved for the establishment of the Tobacco Control Fund using a surcharge, which is called compulsory contribution, applied at 1\% from May 2013; 1.5\% from 2016 and $2 \%$ from 2019. In 2015, 67 units of 63 provinces/cities, 22 ministries and political-social organizations and 6 hospitals have received funding from TCF to implement prevention and control of tobacco harms measures. This is a good achievement of Vietnam thanks to the continuing efforts of all the tobacco control partners in Vietnam for the past decades.

Since, the SCT in Viet Nam has been applied to factory price, the tax burden when calculated as percentage of retail price, for standardized international comparison, becomes quite low. At the tax rate of 2015 (which is 65\%) together with VAT, the total tax burden of Vietnam only equals to $42.6 \%$ of the retail price. Hence, the tax rate on tobacco in Vietnam is quite far from the optimal level of $70 \%$ of retail price as recommended by WHO.

\section{Discussion}

Concerning monitor tobacco use and prevention policies (corresponding to Article 20 FCTC - Research, surveillance and exchange of information, as recommended from Article 20 that "the Parties shall establish appropriate programs for national, regional and global surveillance", Vietnam has actively participated in the global surveillance system to monitor tobacco use and related issues such as the violation of the bans on tobacco advertisement, implementation of graphic health warnings in order to oversee the impact of tobacco control law and provide evidence to suggest future policies. With the technical and financial support from CDC and WHO, two important surveys Global Youth Tobacco Survey and Global Adult Tobacco Survey have been repeated regularly as requested (three times for GYTS and two times for GATS), providing important and good quality data for policy advocacy, and for evaluating the implementation of tobacco control activities as well as to report to Global Tobacco Control Report (GTCR) regularly. Tobacco Control Fund has started providing co-fund for national surveys and for surveys at provincial level. A long-term plan for monitoring and evaluation of tobacco use situation and the implementation of Tobacco Control Law has been developed. In the future, the implementation of tobacco surveillance system is feasible as the sustainable source of funding can come from the Tobacco Control Fund.

Regarding protection of people from secondhand smoke (corresponding to Article 8 FCTC - Protection from exposure to tobacco smoke), as mentioned in the MPOWER measurement package of WHO, there is no safe level of secondhand smoke so a total ban on smoking in public places is essential. Currently, Vietnam has successfully established and implemented a number of smoke-free environment models including smoke-free 
environments in hospitals, schools and offices. At these smoke-free offices, guidelines, posters and "no smoking" signs have been hung up. Future implementation plan for smoke-free environment has been made. There are many good examples of implementing smoke-free environments including Ha Long, Hai Phong, Thai Binh, Nha Trang, Hue, Hoi An etc. (Vietnam Public Health Association, 2010). Thanks to that, smokers who wanted to quit or reduce smoking have been supported, and non-smokers will be protected from exposure to secondhand smoking with better air quality at different settings.

Raising public awareness and promoting behavior changes are essential to creating smoke-free environments. In Vietnam, in public places such as universities, schools, and hospitals, tobacco control curriculum and guidelines on how an institution could become smoke-free have been added; thus, awareness of the consequences of tobacco use has increased (World Health Organization, 2013).

It is very important for conducting monitoring and supervision to strengthen the enforcement of smoke-free environment. Enforcements have been implemented in $\mathrm{Ha}$ Noi and some other provinces. Inter-sectoral monitoring teams with representatives from health and other relevant sectors have been formed and conducted monitoring. The situation of exposure to second-hand smoke at home (47.7\% in 2014 vs 58.5 in 2007) and in public places (66.5\% in 2014 vs $71.2 \%$ in 2007) has been reduced although still at high levels (GYTS) (Vietnam Ministry of Health et al., 2014). Strengthening monitoring and enforcement of smoke-free environment implementation should be one of the priorities to protect people from harmful effect of secondhand smoke (Centers for Disease Control and Prevention, 2008; Vietnam Public Health Association, 2010).

Even with the mentioned-above achievements, the country is currently facing many difficulties in establishing smoke-free environments at places such as bars or restaurants because of the following reasons: 1) Price of tobacco remains low; 2) issues related to the management of smuggled tobacco remains limited; 3 ) the prevalence of smoking rate among males remains too high and smoking is widely accepted; 4) control of tobacco promotion and marketing is not paid enough attention; 5) law and regulation on the implementation of free-smoking environments have already been established but its enforcement is still weak and there is still lack of cooperation among units in responding to violation penalties (Centers for Disease Control and Prevention, 2008; Vietnam Public Health Association, 2010) .

According to WHO, overall compliance score in 2014 for public places with Vietnamese smoke-free legislation was only 4 out of perfect 10 (World Health Organization, 2015a). Thus, it is important to strengthen law and regulation on enforcement and compliance. Promoting people's perception on the consequences of second-hand smoking and tobacco control issues through communication activities at schools, hospitals, and other public places and improving the capacity of agencies responsible for planning, implementing and monitoring activities in different provinces are also recommended.

Regarding support to quit tobacco use (corresponding to FCTC Article 14 - Demand reduction measures concerning tobacco dependence and cessation), basically, smokers are considered to depend on nicotine and it is very challenging for them to quit using tobacco. According to the GATS 2010 , only $29.3 \%$ of people, who had history of using tobacco had quit smoking successfully and 55.3\% of the smokers had made an attempt to quit but did not abandon their dependence on nicotine (Vietnam Ministry of Health et al., 2010). Therefore, the national health care systems take responsibility for assisting the smokers out of their nicotine dependency. According to WHO, there are some standards in evaluating a nation's system of cessation services or nicotine treatment, including the availability of NRT treatment, non-NRT treatment, reimbursement for the mentioned services and a national toll-free quit line.

With the support from Vietnam Tobacco Control Fund, cessation activities have been newly implemented, with cessation services established in 5 hospitals and one tollfree quite line established at Bach Mai Hospitals with 10 counsellors providing cessation advice through the phone. However, the care of tobacco cessation at health care facilities based is still limited, only $34.9 \%$ of smokers, were asked about their history of tobacco use and less than one third of them $(29.7 \%)$ received advice to quit smoking (Vietnam Ministry of Health et al., 2010). Generally, the compliance of Vietnam's legislation to FCTC's article 14 is now just at the beginning level and NRT is not covered by health insurance. It is very important to build capacity for health professional on quick advice and cessation treatment to strengthen the effect of cessation support of health system. A national guideline on tobacco cessation has been developed and should be approved soon.

With regard to warning of dangers (corresponding to Article 11 - Packaging and labelling of tobacco products), though it has been more than 2 years since the implementation of PHWs, research on the impact of the new PHW set is very limited but yet, the results showed very promising effects. According to the Hanoi Medical University's report to International Development Research Centre (IDRC), while changing from text-only health warnings to PHWs, the reductions in demand for cigarettes range from $3.8 \%$ to $10 \%$. For non-smokers, the new cigarette pack with lung cancer pictures had the strongest and the most significant impact on preventing participants from smoking initiation $(12.2 \%, 95 \% \mathrm{CI}: 8.3 \%-17.1 \%)$ (Minh et al., 2015). This report also projected that 400,000 - 600,000 deaths would be prevented and more than 4 billion dollars (which accounted for around $3 \%$ of Vietnam GDP in 2014) would be saved due to the impact of the PHWs (Minh et al., 2015). Another study showed a strong positive association between the level of cognition related to PHWs and the intention to quit of smokers $(\mathrm{OR}=2.8$; 95\% CI: 1.8 - 4.3) (Tran and Meyrowitsch, 2015). In this study, the strongest predictor for a quit intention was reported as "Ever made a quit attempt" $(\mathrm{OR}=7.03 ; 95 \%$ CI: 4.5 - 10.2) followed by being "Very worried about the health consequences" $(\mathrm{OR}=4.1 ; 95 \% \mathrm{CI}: 1.5-11.3)$ (Tran 
and Meyrowitsch, 2015).

Nevertheless, challenges remain. First of all, according to a conference presentation of Vietnam Public Health Association, the salience of the PHWs is reducing through time. Moreover, smokers are trying less to avoid the PHWs and less willing to buy the cigarette pack without PHWs if it is not available at the time of purchase or is more expensive compared to cigarette packs that have PHWs.

Counter methods from the tobacco industry vary. For example, they change the design of the cigarette pack into different shapes rather than the rectangular shape to destroy the image of PHWs; they use the loophole of the law to use the tax stamp to cover a part of the PHW; they only wrap several cigarette packages with a nylon film (instead of packing the cigarette packages into cartons) so that there is no need to print the PHWs; they provide metal cases/boxes in which smokers can use to cover the PHWs as a gift for purchasing their products etc.

Another obstacle comes from the smuggling of tobacco from neighboring countries like Cambodia and Laos where the price is not only cheaper but there are also no pictorial health warnings on the cigarette packages (only text-based warnings).

In summary, Viet Nam has been implementing PHW effectively in the last 3 years. In order to maintain and strengthen the impact, the government should consider changing the set of warning pictures to refresh them, and to increase the size of warnings. In the future, Viet Nam should also consider plain packaging following the example of Australia and other countries. Last but not least, anti-smoking campaigns using the image of PHWs should be done periodically to support the maintenance of PHWs' salience. Information on counseling/treatment services such as quit line call number or counselling office call number which will support quitting should also be printed on cigarette packages along with the PHWs.

Regarding enforcing the TAPS ban (corresponding to Article 13 - Tobacco advertising, promotion and sponsorship), overall, the good compliance with the TAPS ban in the mass media needs to be maintained. However the enforcement at POSs should be seriously strengthened. This is a complex task and facing obstacles such as the lack of human resources for inspection, retailers are not aware of their violations, interference from tobacco industry. In order to implement the TAPS ban effectively, the cooperation of related stakeholders like the Ministry of Health, the Ministry of Industry and Trade (especially Market Surveillance Agency), the Ministry of Information and Communication etc. are necessary; sanctions should be higher; more human resources and effort should be put into inspection and communication to raise awareness of retailers and smokers, which is essential.

Regarding raising taxes on tobacco, though the price of cigarettes has been raised noticeably, the products are becoming more affordable, especially in middle-low income countries. The situation also occurred in Vietnam, a pack of cigarette is just expensed at $0.5 \%$ of average GDP per capital per month (GDP/capital 2015: PPP\$ 5,370 and retail price/ pack of 20 cigarettes: PPP\$ 1.8) (World Bank, 2015; World Health Organization, 2015a). Hence, raising tax on tobacco to increase its retail price is required. Study showed that cigarette excise tax levels and prices are lower for a purely ad valorem system (World Health Organization, 2015b). Thus, transferring from a system that relies heavily on ad valorem excise into a mixed system of specific and ad-valorem excise tax would be a good solution for Vietnam in raising the retail price on tobacco products and reduce consumption.

In conclusion, with countless efforts, Vietnam has gained many fruitful achievements. However, the roadmap towards success on tobacco control and prevention still has a lot of impediments. Therefore, it is essential to highlight that Vietnam should raise efforts to implement tobacco control legislation that fully complies with the Framework Convention on Tobacco Control. In order to achieve this, Vietnam should prioritize resources for capacity building for strong FCTC compliant legislation, including strengthening the monitoring system of these 6 mentioned MPOWER policies: a national surveillance system; communication campaigns; actions to sustain and strengthen the salience of the PHWs; promoting and expanding the coverage of the existing toll-free quit line; actions to control advertisement, promotion, sponsorship, and smuggled cigarettes; and implementing a mixed system of specific and ad-valorem excise tax.

\section{Acknowledgements}

We acknowledge the financial support and coordination of the Hanoi School of Public Health, World Health Organization and the Tobacco Control Research group of Viet Nam Tobacco Control Fund. We would like to thank Phuong Tran for performing English editing of this paper. We would like to express our sincere appreciation to Dr. Malcolm Moore, the Editor in chief of the Asian Pacific Journal of Cancer Prevention, for his great input to this paper.

\section{References}

Anh LV, Thanh Huong LT, Tuyet Hanh TT, et al (2010). The compliance of tobacco advertising, promotion and sponsorship bans in Viet Nam, 2010. Vietnam J Public Health, 8.

Anh PTH, Thu LT, Ross H, et al (2014). Direct and indirect costs of smoking in Vietnam. Tob Control, 10, 1136.

Bich NN, Son DM (2006). The views of consumers about the health warnings on cigarette packet. Vietnam J Public Health, 5, 8-14.

Centers for Disease Control and Prevention (2008). Annual Smoking-Attributable Mortality, Years of Potential Life Lost, and Productivity Losses - United States, 2000-2004. Morbidity Mortality Weekly Report, 57, 1226-8.

Duy KV (2004). Research on interest, belief of community towards the displayed format of health warnings on cigarette packages. Health Bridge Canada, Language: Vietnamese.

Jamison DT BJ, Measham AR, et al., (editors) (2006). Disease Control Priorities in Developing Countries Washington (DC): World Bank.

Levy DT, Bales S, Lam NT, et al (2006). The role of public policies in reducing smoking and dealths caused by smoking in Vietnam: Results from the Vietnam tobacco policy simulation model. Soc Sci Med, 62, 1819-30.

Mathers CD, Loncar D (2006). Projections of global mortality 
and burden of disease from 2002 to 2030. Plos Med, 3, 442 .

Minh HV, Giang KB, Chung LH (2015). Assessing health, economic and social equity impacts of graphic health warning label interventions in Viet Nam. Hanoi, Vietnam: Hanoi Medical University.

Ministry of Finance. Circular No. 168/1998/TT-BTC of December 21, 1998, guiding the implementation of Decree No.84/1998/ND-CP of october 12, 1998 of the Government detailing the implementation of the special consumption tax (SCT) law. Language: Vietnam.

Ministry of Health, International Development Enterprise IDE (2006). Research and Development of a new system of health warnings on cigarette packages in Vietnam. Final Report.

Ministry of Industry and Trade. Circular No. 37/2013/TT-BCT dated December 30,2013, stipulating the import of cigarettes and cigars. Language: Vietnam.

Ministry of Trade, The Ministry of Industry. Joint circular No. 01/2007/TTLT-BTM-BCN of January 10, 2007 guiding the import of cigarettes and cigars prescribed in The Government's Decree No. 12/2006/ND-CP of January 23, 2006, detailing the implementation of the commercial Law regarding international goods sale and purchase and goods sale, purchase, processing and transit agency activities with foreign countries. Language: Vietnam.

Mokdad AH, Marks JS, Stroup DF, et al (2004). Actual causes of death in the United States. JAMA, 291, 1238-45.

National Assembly of Vietnam. Law on the Protection of People's Health.

National Assembly of Vietnam. Law No. 57/2005/QH11 of November 29, 2005 amending and supplementing a number of articles of The Special Consumption Tax law and The Value Added Tax Law. Language: Vietnam.

National Assembly of Vietnam. Law No. 09/2012/QH13 of June 08, 2012, on tobacco harm prevention. 09/2012/QH13. Government document. Language: Vietnamese.

National Assembly of Vietnam. Law No. 70/2014/QH13 dated November 26, 2014, amendments to some articles of the Law on special excise duty. Language: Vietnam.

Prime Minister of Vietnam. Directive No. 12/2007/CT-TTg date May 10, 2007 of the Prime Minister on intensifying tobacco harm prevention and combat activities. 12/2007/CT-TTg. Government document.

Shelley D, Nguyen L, Pham H, et al (2014). Barriers and facilitators to expanding the role of community health workers to include smoking cessation services in Vietnam: a qualitative analysis. BMC Health Serv Res, 14, 606.

Solberg LI, Maciosek MV, Edwards NM, et al (2006). Repeated tobacco-use screening and intervention in clinical practice: health impact and cost effectiveness. Am J Prev Med, 31, 62-71.

Tran DT, Kosik RO, Mandell GA, et al (2013). Tobacco control in Vietnam. Public Health, 127, 109-18.

Tran N, Meyrowitsch DW (2015). The Association Between Pictorial Health Warnings And Quit Smoking Intention Among Male Smokers In Vietnam. Abu Dhabi, United Arab Emirates: 2015 17-21 March. Report No.

U.S. Department of Health and Human Services, Centers for Disease Control and Prevention (2010). Surgeon General Report. How tobacco smoke causes disease.

Vietnam Ministry of Cultural Information and Communication. Circular No 37-VHTT-TT dated 01-07-1995 instruct the implementation of Decree 194/CP about advertising activities on Vietnamese territory. 37-VHTT-TT. Document number.

Vietnam Ministry of Health. Impact of health warnings on cigarette packages on smokers. 2000a. Language: Vietnamese.
Vietnam Ministry of Health. Mandatory labeling requirements on cigarette packages. 2019/2000/QĐ-BYT. Government document. Language: Vietnamese.

Vietnam Ministry of Health. National Health Survey 20022002.

Vietnam Ministry of Health, Center for Community Development and Research (2009). Research on the compliance and effectiveness of the current health warnings on cigarette packs in Vietnam.

Vietnam Ministry of Health, Hanoi Medical University, General Statictis Office, et al Global Adults Tobacco Survey GATS. Hanoi, Vietnam: 2010. Language: English.

Vietnam Ministry of Health, Hanoi Medical University, General Statictis Office, et al Global Youth Tobacco Survey GYTS. Hanoi, Vietnam: 2014. Language: English.

Vietnam Public Health Association. Annual report 2010. 2010. Vietnamese Government. Decree No.194-CP on 31st December 1994 on advertising activities on Vietnamese territory. 194/ CP. Government document.

Vietnamese Government. Resolution No. 12/2000/NQ-CP dated August 14, 2000 of the Government on "national tobacco control policy" in the period 2000-2010. 12/2000/NQ-CP. Government document.

Vietnamese Government. Decree No. 45/2005/ND-CP dated April 6, 2005 of the Government providing for the sanctioning of administrative violations in the field of health. 45/2005/ND-CP. Government document.

Vietnamese Government (2013a). Decree 176 on administrative sanctions for violations in health sector.

Vietnamese Government. Decree No. 77/2013/NDD-CP of detailing impelentation of the law on tobacco harm prevention regarding some measures of tobacoo harm prevention.

World Bank (2015). Data of GDP per capita, PPP (constant 2011 international \$) [Online].

World Health Organization 2005. Framework Convention on Tobacco Control (FCTC), Geneva, Switzerland, WHO Press.

World Health Organization 2008. WHO report on the global tobacco epidemic: The MPOWER package, Geneva, Switzerland, WHO Library Cataloguing-in-Publication Data.

World Health Organization. WHO REPORT ON THE GLOBAL TOBACCO EPIDEMIC, 2009 Implementing smoke-free environments. 2009.

World Health Organization. WHO REPORT on the Global Tobacco Epidemic, 2011 Warning about the dangers of tobacco. 2011.

World Health Organization. WHO report on the global tobacco epidemic: MPOWER in action - Defeating the global tobacco epidemic. Geneva, Switzerland: 2013.

World Health Organization. Report on the Global Tobacco Epidemic: Vietnam Country profile. Geneva, Switzerland: 2015a.

World Health Organization. WHO report on the global tobacco epidemic, 2015: Raising taxes on tobacco. Geneva, Switzerland: 2015 b.

World Lung Foundation. Vietnam Health Communications Campaigns. 2015. Available from: http://www. worldlungfoundation.org/ht/d/sp/i/17730/pid/17730/ cat_id/5707. 